\title{
Hundred years of research on inversion polymorphism in Drosophila
}

\author{
B. N. Singh* \\ Genetics Laboratory, Department of Zoology, Institute of Science, Banaras Hindu University, Varanasi 221005 , India
}

\begin{abstract}
Paracentric inversions are widespread in the genus Drosophila. Naturally occurring chromosome inversions were detected very early indirectly as far as genetics history is concerned. Sturtevant in 1917 found that in certain strains of $D$. melanogaster reduced recombination was due to inversions in order of genes in chromosomes, a proposal which was subsequently verified by him in 1926 and 1931 based on the data of genetic mapping. The physical reality of chromosomal inversions was confirmed with the discovery of giant salivary gland chromosomes in Drosophila by Painter in 1933. From which the gene order could be known from the banding pattern. Since the initial work of Sturtevant in 1917 on inversions in Drosophila, hundred years have lapsed and chromosomal polymorphism due to inversions in a large number of species of the genus Drosophila has been extensively studied by using polytene chromosome maps. About one hundred species of Drosophila have been found to be chromosomally polymorphic. Hundred years of research on inversion polymorphism in Drosophila have revealed that inversions in Drosophila are important from view point of population and evolutionary studies. This review briefly summarizes the important findings pertaining to the research of hundred years on inversion polymorphism in different species of Drosophila.
\end{abstract}

Keywords: Drosophila, genetic coadaptation, inversion polymorphism, population dynamics.

IN chromosomes, structural and numerical changes are known to occur widely in plant and animal species, including humans ${ }^{1}$. Chromosome arrangements have significant role in the process of speciation in various types of population ${ }^{2}$. Among different types of numerical alterations in chromosomes, polyploidy which is common in plants has played a significant role in speciation and many species of plants have evolved due to the occurrence of polyploidy ${ }^{3}$. In structural changes in chromosomes, inversions and translocations are known to occur in many cases, and have been studied with particular reference to genetics, cytogenetics and evolution ${ }^{1}$. The occurrence of paracentric inversions in Drosophila, pericentric inversions in grasshoppers and crickets, and translocations in Oenothera is noteworthy. Translocation heterozygotes in Oenothera lamarckiana were used as a

\footnotetext{
*e-mail: bnsinghbhu@gmail.com
}

basis of mutation theory of evolution by de Vries ${ }^{4}$. Detailed study on pericentric inversions has been conducted in grasshoppers from Australia and their significance has been discussed from the evolutionary point of view $^{3}$. Paracentric inversions are of common occurrence in Drosophila and have been extensively studied. However, there are reports about translocation and pericentric inversions in Drosophila, but these are rare ${ }^{5-7}$. Inversions in Drosophila melanogaster were initially detected quite early in the genetics history ${ }^{8}$. Sturtevant ${ }^{9}$ found that in certain strains of $D$. melanogaster, reduced recombination in chromosomes was due to inversions in the order of genes on a chromosome, a proposal which was experimentally verified by him in 1926 (ref. 10) and 1931 (ref. 11) with the help of genetic mapping data. Dicentric and acentric fragments produced due to crossing-over within the paracentric inversion in a heterozygote are eliminated through polar bodies in females, and the egg receives only a normal non-recombinant chromatid ${ }^{12}$. Thus recombinants are not observed. The gametes produced by single crossover event between the breakpoints would never be recovered in progeny. As a consequence, inversions are inherited intact as a single Mendelian unit. In population genetics studies, various gene arrangements are treated as alleles at a single locus. Furthermore, crossing-over may be strongly suppressed within the inversion in heterozygotes. Drosophila is characterized by the absence of crossing-over in males. Thus, fertility is not lowered by paracentric inversions. Because of these reasons, paracentric inversions are cytologically neutral. The giant polytene chromosomes in Drosophila were detected and chromosome maps were constructed on the basis of banding pattern in D. melanogaster for the first time $\mathrm{e}^{13-17}$. Subsequently, cytological chromosome maps were constructed in a number of species which helped to detect a large number of inversions. From that time, population genetics studies on inversion polymorphism were initiated in various species of Drosophila. It has been reported that numerous Drosophila species show polymorphism for naturally occurring inversions, but there are monomorphic species also not showing the presence of inversion polymorphism ${ }^{8}$. A large number of species of the genus Drosophila have been employed to study population dynamics of inversion polymorphism in detail. These are: D. pseudoobscura, D. persimilis, D. willistoni, D. robusta, D. subobscura, D. melanogaster, D. ananassae, 
D. funebris, D. pavani, D. rubida, D. nasuta, D. flavopilosa, D. azteca, D. hydei, D. buzzatii, D. buscki, D. immigrans, D. mercaturum, D. nebulosa, D. paulistorm, D. bipectinata, D. guaramunu, D. prosaltans, D. athabasca, $D$. algonquin, $D$. virilis, $D$. repleta, etc. If one surveys the literature in respect of inversion polymorphism in these species of Drosophila, one fact is evident that there is much variation in the pattern of inversion polymorphism in different species of the genus. Interestingly, sometimes very closely related species have been found to differ in the degree of inversion polymorphism with respect to both, intra and interspecific variations. At the same time, certain species which were studied for chromosomal variability were found to be almost monomorphic ${ }^{18}$. Based on his extensive studies in natural populations of D. pseudoobscura, Dobzhansky ${ }^{19}$ was the first to demonstrate that inversion polymorphism is subject to natural selection. While extending his work in D. pseudoobscura, Dobzhansky showed that inversions play an important role in adaptation of populations to varying environments. Further, he also demonstrated that polymorphism is balanced due to adaptive superiority of inversion heterozygotes, and different gene arrangements of the same chromosome are mutually adjusted or coadapted due to action of natural selection in a population and that inversions show seasonal variation in their frequencies ${ }^{20}$. Random genetic drift may also cause changes in gene arrangement frequencies in populations. Dobzhansky et $a l .^{21}$ and Da Cunha and Dobzhansky ${ }^{22}$ also suggested the ecological niche hypothesis which states that inversion polymorphism in Drosophila is a device to cope with the diversity of the environment. Further, Carson ${ }^{23}$ has shown the differences between central and marginal populations of D. robusta while comparing the degree of chromosomal variability. Inversions also affect crossing-over, which has been studied cytologically and genetically. Recombination may be affected by inversions of the same chromosome and also of different chromosomes. Inversions of the same chromosome often occur in non-random associations $^{24,25}$. It has also been shown that chromosome inversions may have partial behavioural basis and may affect various fitness traits ${ }^{26,27}$. Research on inversion polymorphism is still being pursued in different species, and it has also been correlated with molecular data with particular reference to allozyme and DNA polymorphisms $^{28,29}$. In this article, the research on inversion polymorphism in Drosophila conducted during the last 100 years is discussed, which shows that chromosome inversions in the genus are important from the viewpoint of population genetics and evolutionary studies.

\section{Population dynamics of inversion polymorphism in natural populations of different species}

Paracentric inversions may be of different types independent, overlapping and included, which have been reported in different species. D. pseudoobscura and D. persimilis, a pair of sibling species are unique in the sense that a large number of overlapping inversions have been detected in them, which have been used for different kinds of studies: population differentiation, seasonal changes, heterosis, balanced polymorphism, genetic coadaptation, role of natural selection, genetic drift and inversion phylogeny. Dobzhansky ${ }^{19}$ conducted extensive studies on inversion polymorphism in D. pseudoobscura, and found that inversion frequencies showed annual cyclic changes (also inversion clines), thus demonstrating adaptive function of inversion polymorphism. This was the first demonstration of the significant role of selection in maintaining chromosomal polymorphism due to paracentic inversions in Drosophila natural populations ${ }^{19}$. Inversion polymorphism has been studied in both the sibling species, but data are more extensive in $D$. pseudoobscura than in D. persimilis. Further, D. pseudoobscura is chromosomally more polymorphic than D. persimilis ${ }^{30}$.

Dobzhansky et al. ${ }^{21}$, and Da Cunha and Dobzhansky ${ }^{22}$ studied inversion polymorphism in four sibling species of the willistoni group in Brazil: D. willistoni, D. paulistorum, D. tropicalis and D. equinonoxialis. There were intra- and interspecific variations in the level of inversion polymorphism. Mean number of herozygous inversions showed good correspondence with environmental heterogeneity in Drosophila populations. Marginal populations showed a lower degree of inversion polymorphism than those in the centre of geographical distribution. On the basis of these results, Dobzhansky and co-workers suggested the ecological niche hypothesis which states that inversion polymorphism is a method to adapt with environmental diversity. The inversion frequencies have also been compared between rural and urban populations in certain species. Interestingly, the inversion frequencies are lower in rural as populations as compared to urban populations in D. funebris, which is correlated with ecological opportunities available to the species ${ }^{31}$.

The geographical patterns of inversion frequencies have been studied in detail in D. robusta ${ }^{23,32,33}$. Carson ${ }^{23}$ compared the degree of inversion polymorphism between central and marginal populations of $D$. robusta by measuring the amount of chromosomal variability by an index of free recombination (IFR - how much of euchromatin is free to undergo recombination). Polymorphism was lower in marginal populations (high IFR) than the central ones (low IFR). IFR decreased from 99.7\% in marginal populations to $67 \%$ in geographically central populations. Carson ${ }^{23}$ suggested that the amount of crossing-over is an essential adaptive factor and that the low level of chromosomal polymorphism in marginal populations where homoselection (selection favouring homozygotes) predominates, gives a high potential for free recombination from which adaptive novelties are synthesized. However, in geographically central populations, there is a high level of chromosomal variability and 
heteroselection (selection favouring heterozygotes) predominates. Thus marginal populations have more adaptability and the central populations have more adaptedness $^{23}$. Levitan ${ }^{32}$ has reviewed the literature, and found the north-south and east-west clines in inversion frequencies in natural populations of D. robusta.

Chromosomal polymorphism due to paracentric inversions has been studied in detail in D. subobscura, an Old World counterpart in certain ways to $D$. pseudoobscura by European researchers ${ }^{6,34-37}$. In this species, five acrocentric chromosomes are designated by vowels - A, E, I, $\mathrm{O}$ and $\mathrm{U} ; \mathrm{A}$ is the $\mathrm{X}$ chromosome and $\mathrm{J}$ is often substituted for I. Paracentric inversions are known to occur in all the chromosomes. This species is highly polymorphic; more that 50 paracentric inversions are known in the species and there are interpopulation variations in the inversion frequencies ${ }^{6,8,36}$. There are clines in the inversion frequencies, but they show variations for different inversions. Most likely selection is related to latitudes. Interestingly, later on this Old World species was found in Chile, Argentina and USA ${ }^{36,38-40}$. From the data on inversion frequencies, it was suggested that the source of North American invasion was South America. The invasion of New World by a Drosophila species of the Old World has been called 'a grand experiment in evolution' by Ayala et $\mathrm{al}^{39}$. From the results, it is apparent that latitudinal gradients found in the Old World populations have been established in the populations of South America in the exactly reverse order ${ }^{40}$. Thus these results clearly demonstrate that selection related to latitude is operating to maintain the inversion frequencies in natural populations of D. subobscura.

D. melanogaster is a cosmopolitan and domestic species. It was used in genetic studies for the first time in 1909 by Thomas Hunt Morgan, who proposed the theory of linkage and discovered spontaneous white-eyed sex-linked recessive mutation in this species for the first time. It has been extensively used as the best biological model for various kinds of studies in genetics, cytogenetics, population genetics, behaviour, ecology, evolution, molecular biology, etc. Inversion polymorphism in this species has been extensively studied by numerous researchers at the global level and has been found to be highly polymorphic chromosomally. Among all the species studied, it shows the highest degree of chromosomal polymorphism as it contains more than 300 paracentric inversions ${ }^{41-54}$. Naturally occurring inversions in D. melanogaster have been classified into four types: common cosmopolitans, rare cosmopolitans, recurrent endemics and unique endemics ${ }^{43,49,55}$. Inversion polymorphism has also been studied in Indian populations of D. melanogaster and 42 inversions have been detected ${ }^{49}$. There is geographic differentiation in the frequencies of four common cosmopolitan inversions at the global level, and inversion frequencies have been correlated with environmental conditions and ecological niches which change with latitude. Thus latitudinal clines are found in the inversion frequencies in both the northern and southern hemisphere ${ }^{43,45-48,50,52-54,56,57}$. Thus extensive studies in this cosmopolitan and domestic species have clearly demonstrated that inversion polymorphism is adaptively important, even though species differs from other cosmopolitan and domestic species in this respect ${ }^{6,28,53,58}$.

D. ananassae is a cosmopolitan and domestic species, but it is mainly circumtropical in distribution. It is of common occurrence in India. It is a genetically unique species characterized by several unusual genetic features $^{59-61}$. The most unusual genetic feature of this species is the presence of spontaneous male recombination which is meiotic in origin ${ }^{62}$. Chromosomal polymorphism in this species has been studied in detail ${ }^{63-73}$. Chromosomally, it is highly polymorphic: 78 paracentric inversions, 21 pericentric inversions and 48 translocations have been reported so $\operatorname{far}^{60}$. In this species, numerous paracentric inversions are known, but only three paracentric inversions: AL (alpha) in $2 \mathrm{~L}(\operatorname{In}(2 \mathrm{~L}) \mathrm{A}$ or subterminal), DE (delta) in $3 \mathrm{~L}(\operatorname{In}(3 \mathrm{~L}) \mathrm{A}$ or terminal) and $\mathrm{ET}$ (eta) in $3 \mathrm{R}(\operatorname{In}(3 \mathrm{R}) \mathrm{A}$ or basal) are considered as cosmopolitan inversions and are co-extensive with the species considering the monophyletic origin of these inversions. Singh $^{64}$ detected these three cosmopolitan inversions from different localities in India, including the Andaman and Nicobar Islands and showed the geographic distribution of these inversions at the global level. Population genetics of three cosmopolitan inversions in Indian populations of $D$. ananassae has been extensively studied by Singh and co-workers ${ }^{65-67,71}$. The results provide evidence that the inversion frequencies vary in Indian natural populations of $D$. ananassae. The level of evolutionary divergence has been quantified by calculating genetic distance $(D)$ and genetic identity $(I)$, which have demonstrated that Indian populations show considerable degree of genetic divergence at the level of inversion polymorphism. Further, in general, the South Indian populations show greater level of divergence compared to those from the North ${ }^{6770-72,74-76}$. Interestingly, the populations from Kerala, and Andaman and Nicobar Islands show greater level of similarity. The level of heterozygosity also varies in different populations. There is a strong genetic differentiation and minimal gene flow in this cosmopolitan and domestic species between populations, which extends evidence that Indian populations of $D$. ananassae show strong sub-structuring associated with inversions ${ }^{77}$. Reddy and Krishnamurthy ${ }^{78}$ reported significant differences in the frequencies of inversion heterozygotes in Nilgiri range in South India; the frequencies were different at different altitudes. Interestingly, an inversion within the subterminal inversion was reported in a laboratory stock of D. ananassae obtained from Kuala Lumpur, Malaysia (Figure 1) ${ }^{79}$.

Further, it has also been reported that in D. ananassae, body size is controlled by polygenes and inversion 


\section{REVIEW ARTICLES}

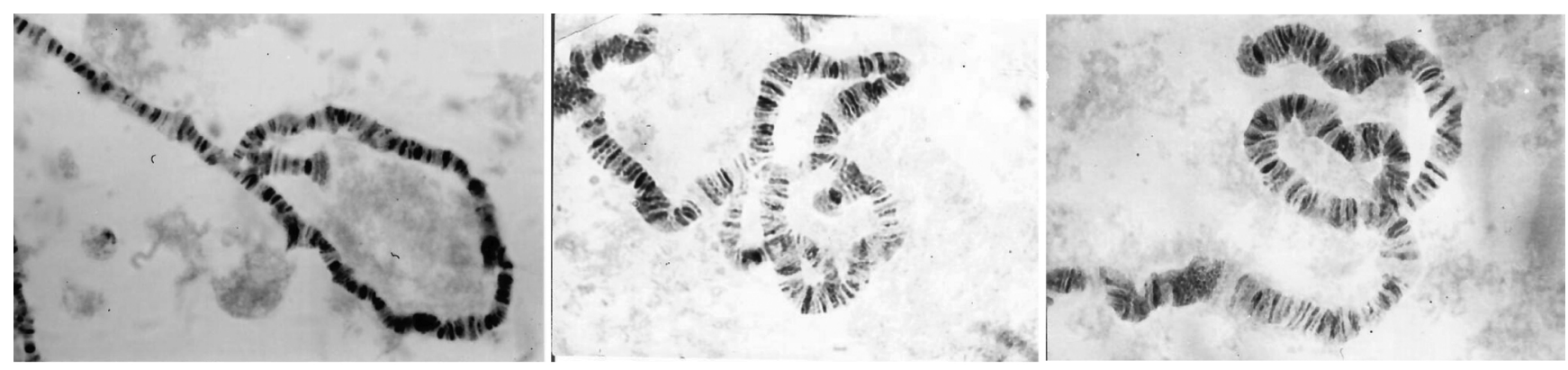

Figure 1. Photomicrographs of heterozygous inversions detected in a laboratory stock of Drosophila ananassae ${ }^{79}$.

polymorphism is important in the maintenance of body size which is caused due to modification in the frequency of genotypes under different regimes of selection ${ }^{80}$. The three cosmopolitan inversions in $D$. ananassae could spread and become established in worldwide populations because of heterotic combinations of genes occurring within the inverted segments, and they have become a part of the adaptive machinery in natural populations of this species.

In the D. bipectinata species complex, there are four species, viz. D. bipectinata, D. malerkotliana, D. parabipectinata and $D$. pseudoananassae. Inversion polymorphism has been studied in natural and laboratory populations of all the four species ${ }^{81-93}$. A large number of paracentric inversions have been reported in these species. Frequencies of inversions do not differ in different geographic populations of $D$. bipectinata, which provides no evidence for geographic differentiation of inversion polymorphism in Indian populations, and suggests that inversion polymorphism is rigid in D. bipectinata $^{86}$. In hybridization experiments, inversions have been used to discuss the phylogenetic relationship among the four species of this complex ${ }^{81,82,89-92}$. In all the studies, one fact is clear that D. bipectinata, D. parabipectinata and D. malerkotliana are closely related with each other and $D$. pseudoananassae is distantly related to these three species, but other details of their phylogeny do not match with each other ${ }^{92}$. Inversion polymorphism is known to occur in D. nasuta, in which there is evidence for geographic differentiation and altitudinal clines in Indian natural populations with respect to inversion polymorphism $^{94-96}$. Carson $^{97}$ discussed the pattern of chromosomal polymorphism in geographically widespread species of Drosophila, and found variation in the pattern of inversion polymorphism in different species. Evidence for rigid inversion polymorphism has been presented in D. pavani in which there is homogeneous inversion polymorphism in various natural populations ${ }^{98,99}$. Seasonal changes in the inversion frequencies have been found in D. rubida ${ }^{100}$, D. flavopilosa ${ }^{101}$, D. funebris ${ }^{102}$ and a few other species, which give evidence for flexible inversion polymorphism ${ }^{8}$.

\section{Behaviour of inversions in laboratory populations, heterosis and balanced polymorphism}

From the flies collected from nature, laboratory strains are established. In different species, chromosomal analysis of strains was done to identify inversions. These strains were maintained for a large number of generations by transferring the flies to new food bottles in the laboratory. Again they were analysed chromosomally to check the persistence of inversions. Such types of studies have been made in different species. Using homozygous lines for different arrangements, population cage experiments were also conducted in the laboratory. Some examples of such studies are given in this article.

Chromosome inversions persist for many years in laboratory strains in a number of Drosophila species. Levene and Dobzhansky ${ }^{103}$ reported that inversions persisted in laboratory populations for many years in D. pseudoobscura due to higher Darwinian fitness of inversion heterozygotes. Similar results were also reported by Brncic ${ }^{104}$ in D. pavani. In D. pseudoobscura, population cage experiments were conducted employing various third chromosome gene arrangements, and it was found that polymorphism was balanced due to heterosis, i.e. higher Darwinian fitness of heterozygotes and different gene arrangements were maintained at equilibrium frequencies ${ }^{105}$. More or less similar situation was observed in D. persimilis ${ }^{106}$ and D. robusta ${ }^{107}$. In D. pseudoobscu$r a$, random genetic drift and founder effect may cause changes in the frequencies of inversions in laboratory populations $^{108}$. In $D$. ananassae also, the adaptive superiority of inversion heterozygotes leads to balanced inversion polymorphism ${ }^{109,110}$. In $D$. ananassae, three cosmopolitan inversions AL, DE and ET, frequently persist in laboratory stocks due to heterosis exhibited by them ${ }^{111}$. In $D$. ananassae, inversion frequency may change due to random genetic drift ${ }^{112}$, and laboratory populations established from the naturally impregnated females may diverge to different degrees due to the effect of random genetic drift ${ }^{113}$. In D. melanogaster, persistence of inversions was observed ${ }^{114}$. However, when laboratory populations were initiated with naturally impregnated females, a 
decline in the frequency of inversions associated with decreasing heterozygosity was observed and some inversions were found to be completely eliminated in certain mass culture populations of $D$. melanogaster ${ }^{115}$. Different laboratory populations diverged to different degrees due to the effect of genetic drift and founder effect ${ }^{115}$. Singh and Banerjee ${ }^{116}$ also found the persistence of inversions in laboratory populations of $D$. bipectinata. When the level of inversion heterozygosity and frequency of inversions in laboratory populations were compared with those in corresponding natural populations, it was found that there was increasing trend in their frequencies and heterozygosity level. This was caused due to adaptive superiority of inversion heterozygotes under strong competition in the laboratory conditions. This clearly demonstrates that in D. bipectinata, inversion polymorphism exhibits heterosis ${ }^{116}$.

\section{Inversions and genetic coadaptation}

Using inversion polymorphism in D. pseudoobscura, Dobzhansky $^{105,117-119}$ showed that when crosses were made involving strains coming from the same natural populations but having different gene arrangements in chromosomes, heterosis was observed. However, there was breakdown of heterosis in interracial hybridization experiments in D. pseudoobscura. A large number of homozygous lines with different chromosome arrangements in the third chromosome of $D$. pseudoobscura were employed by Dobzhansky. The breakdown of heterosis in interstrain crosses was explained by Dobzhansky ${ }^{105,117}$ advocating the hypothesis of genetic coadaptation. According to this concept, "in each locality the chromosomes with different gene arrangements are coadapted or mutually adjusted to yield highly fit inversion heterozygotes through the process of long continued natural selection. On the other hand, this adaptive superiority of inversion hetarozygotes is broken down in interstrain crosses when two different chromosome arrangements are coming from different geographic localities'. Genes are organized in functional gene comples or supergenes ${ }^{120}$. The supergenes confer higher Darwinian fitness to the genotype. The relative selective values can be assigned to the whole genetic system and evolution depends on gene effects which fit together in a harmonious system ${ }^{121}$. Balanced polymorphism and epistatic selection act together to generate polygenic complexes (supergenes), and in this way form a major feature of evolutionary change $^{122}$. Dobzhansky, who suggested genetic coadaptation hypothesis on the basis of experimental results observed in D. pseudoobscura, is considered as the main architect of this hypothesis. The concept of genetic coadaptation proposed by Dobzhansky, who is popularly known as the 20 th century Darwin ${ }^{123}$, has received support from experimental results concerning interracial hybridization experiments involving chromosomally polymorphic strains derived from natural populations in different species of Drosophila - D. willistoni, D. paulistorum, D. pavani and D. bipectinata ${ }^{104,124,125}$. Interestingly, in all these species the superiority of inversion heterozygotes is lost in interstrain crosses. It has been suggested that coadapted polygenic complexes contained in the chromosomes are disrupted due to crossing-over in interstrain crosses, which leads to the loss of heterosis. In all the four species, the strains polymorphic for inversions derived from natural populations were used. The inversion frequencies were known in their natural populations, which decreased considerably in interracial hybridization experiments after maintaining the hybrid populations in the laboratory for many generations. In general, it was suggested that interracial hybridization leads to breakdown of heterosis as polygenic complexes are disrupted due to crossing-over. Thus superiority of heterozygotes is determined by polygenic complexes which these chromosomes contain, and it is not the necessary consequence of being heterozygous for inversions. Thus, inversions are important to protect the integrity of mutually adjusted polygenic complexes in the chromosomes through the suppression of crossing-over between chromosomes ${ }^{124}$. Natural selection can maintain mutually adjusted polygenic complexes in D. subobscura, which is suggested on the basis of extensive genetic differentiation between different gene arrangements of the $\mathrm{O}$ chromosome ${ }^{37}$. Although evidence in favour of genetic coadaptation hypothesis has been presented in some species, there are some exceptions to this concept. Kumar and Gupta ${ }^{126}$ did not find support in favour of coadaptation hypothesis in natural populations of $D$. nasuta, as there was no breakdown of heterosis in interstrain crosses. D. ananassae is a genetically unique species ${ }^{62}$. Singh ${ }^{70}$ studied extensively chromosomal polymorphism in a large number of Indian populations of $D$. ananassae, and presented evidence for genetic divergence at the level of chromosomal polymorphism. The concept of genetic coadaptation proposed by Dobzhansky was tested in D. ananassae by $\operatorname{Singh}^{127-130}$, who conducted experiments by making different types of crosses using homozygous and chromosomally polymorphic strains. In all the interstrain crosses, there was no breakdown of heterosis. In almost all the crosses, there was persistence of heterosis even though strains from geographically distant localities were used in interstrain crosses. These results clearly demonstrated that the findings in D. ananassae did not agree with those of Dobzhansky and other researchers in different species of Drosophila. Thus, there is no evidence of coadaptation in natural populations of $D$. ananassae. Thus, there is superiority of heterozygotes in $D$. ananassae without previous selectional coadaptation and luxuriance is important in this species ${ }^{130}$. It has been suggested by Singh $^{130}$ that the role of luxuriance is important in D. ananassae and coadaptation of chromosomes does not play any role because heterosis persists in interstain 
crosses. Thus for the organisms to adjust with the environment, luxuriance plays a crucial role ${ }^{130,131}$. Evidence in support of the coadaptation concept has also been provided using molecular data. According to Schaeffer et al. ${ }^{132}$, coadaptation hypothesis has been supported by data with respect to $D$. pseudoobscura third chromosome molecular markers and diversity of nucleotide, and there is the role of epistatic selection. Studies by Hoffmann et $a l .{ }^{133}$ provided evidence that patterns of linkage disequilibrium and variations were consistent with coadapted polygenic complexes and inversions were considered as a dynamic system. It has also been emphasized by them that inversions associated with disequilibrium among loci have the potential to lock up mutually adjusted or coadapted alleles. In a number of species of Drosophila, studies have been reported on linkage disequilibrium between inversions, and also between inversions and allozyme loci which are important to determine the extent of coadaptation. Thus importance of interaction of genes in evoliution is related to coadaptation ${ }^{134,135}$. By studying inversion polymorphism and genetic load in D. subobscu$r a$, evidence for genetic coadaptation has been provi$\operatorname{ded}^{136}$. The linkage disequilibrium inside the inversion and pattern of diversity lend support for coadaptation in D. melanogaster ${ }^{137}$. It has also been demonstrated that in D. pseudoobscura, the chromosomal rearrangement captures a set of genes with different expression levels, which suggests that selection of gene arrangements is important because gene expression is a potential target for $\mathrm{it}^{138}$. The coadapted genome for parthenogenesis is known in D. mercatorum ${ }^{139}$.

\section{Effects of heterozygous inversions on recombination}

Inversions in D. melanogaster were discovered for the first time through their suppressive effects on recombination $^{9-11}$. In D. melanogaster, females show recombination but males do not. When a large number of markers became available, genetic maps were constructed for different chromosomes ${ }^{140,141}$. In different species of Drosophila, inversions have been used to test their effects on recombination. Both types of studies were conducted: using genetic markers and inversions as well as using inversions as markers in cytological studies. Inversions are of two types: paracentric (not including the centromere) and pericentric (including the centromere). Duplications and deficiencies are produced when a single crossover occurs in a heterozygote within the pericentric inversion. However, dicentric and acentric fragments are produced when crossing-over occurs in a heterozygote within paracentric inversion. These are eliminated through polar bodies in females and therefore recombinants are not observed. Further, crossing-over may be strongly suppressed in a heterozygote within the inversion. Hete- rozygous inversions also affect crossing-over outside the inverted area, but different situations have been observed. Inversion heterozygosity prevents recombination not only in the inverted section of the chromosome itself, but also along the rest of the chromosome in D. pseudoobscura ${ }^{142}$. Sturtevant and Beadle ${ }^{143}$ observed a similar situation for some X-chromosome inversions in D. melanogaster. On the other hand, inversion heterozygosity in one arm increases recombination frequency in the opposite arm in D. melanogaster ${ }^{144,145}$. An increase in the frequency of crossing-over in the X-chromosome of D. melanogaster bearing heterozygous inversions was observed by Grell ${ }^{146}$. Komai and Takaku ${ }^{147,148}$ observed that X-chromosome inversions in heterozygous condition had enhancing effects on recombination in the autosomes and also in the terminal regions of the X-chromosome itself. Thus heterozygous inversions of one chromosome strongly enhance the rate of crossing-over in non-homologous chromosomes ${ }^{149-151}$. It has also been observed that when inversions are larger in size, there will be further increase in the frequency of crossing-over in other chromosomes ${ }^{152}$. Lucchesi ${ }^{151}$ has reviewed this phenomenon, and different theories have been suggested to explain how inversions of different chromosomes influence recombination in Drosophila.

Heterozygous inversions influence recombination in $D$. ananassae and both types of effects, viz. intra- and interchromosomal have been found in this species ${ }^{153,154}$. The species is also characterized by male recombination ${ }^{62}$ that is affected by heterozygous inversions, which provides evidence that in $D$. ananassae males crossing-over occurs during meiosis ${ }^{155}$. Crossing-over between linked inversions of the same chromosome has also been studied cytologically in certain species, and the results vary between the species and also between the chromosomes of the same species ${ }^{24,156-160}$. In D. ananassae, crossingover is strongly suppressed between linked inversions of the same chromosome, and distance of chromosome and frequency of crossing-over have no correlation, which is considered as an advantage for species having low degree of heterozygosity of inversion in populations ${ }^{160}$. However, in $D$. willistoni recombination occurs at high frequency between inversions of the same chromosome, which has relation with highly developed adaptive inversion polymorphism $^{156}$.

\section{Non-random associations of linked inversions}

Inversions occurring on the same chromosome have been found to show non-random associations. Levitan ${ }^{161}$ was the first to report that linked inversions in D. robusta occur in non-random associations. The phenomenon of non-random associations of inversions is important from the evolutionary point of view, and known to occur in a large number of species in natural and laboratory 
populations ${ }^{24,25,32}$. This phenomenon has been reported in D. robusta, D. ananassae, D. bipectinata, D. pavani, D. subobscura, D. guaramunu, D. melanogaster, D. rubida, D. nasuta, D. silvestris, etc. ${ }^{25}$. Levitan ${ }^{24}$ pointed out that two main factors, viz. suppression of recombination between inversions and selection operating against recombinant arrangements play an important role for the maintenance of linkage disequilibrium between inversions in different Drosophila species. It has also been suggested that the main factor is natural selection because complete suppression of recombination does not occur if there is a free area available between the inversions. This suggestion of Levitan has received support from different studies in various species of Drosophila. It is interesting to mention that in D. subobscura, the role of both factors has been suggested. Sperlich and Feuerbach-Mravlag ${ }^{157}$ found that non-random associations between two autosomal inversions are due to the absence of recombination. However, selection involving epistatic interaction is important in the case of sex-chromosome inversions. According to these researchers, the chromosome is considered as a functional and selectional unit because natural selection is important in the maintenance of favourable linkages between arrangements. Selection of genes interacting to maximize adaptive fitness results from mutual adjustment of favourable linkages between inversions of the same chromosome ${ }^{135}$. When there is evidence for genetic coadaptation, it also extends support for the evolutionary role of genetic interaction ${ }^{134}$. When non-random association is present, it is mainly attributed to differential selection involving multilocus interaction. Hedrick ${ }^{162}$ has suggested that besides selection, there are other factors which can generate linkage disequilibrium and these are tight linkage, genetic drift, migration, gene flow and genetic hitchhiking. Singh and Singh ${ }^{163}$ have reported that in $D$. ananassae, non-random association between two inversions of the third chromosome is caused by random genetic drift, and strong suppression of crossingover between delta and eta inversions increases the probability of random genetic drift (founder effect).

\section{Behavioural basis of inversion polymorphism}

Inversion polymorphism in Drosophila has been correlated with certain adaptive traits. The different fitness traits are: survival, rate of development, longevity, competitive ability, fecundity, fertility, mating success, etc. ${ }^{6}$. Among these traits, association between mating propensity and inversion karyotypes is important. It was shown for the first time that mating propensity is associated with chromosomal polymorphism in $D$. persimilis ${ }^{164}$. Subsequently, a similar phenomenon was demonstrated in $D$. pseudoobscura, D. persimilis, D. pavani, D. subobscura and D. robusta ${ }^{165-168}$. Ehrman ${ }^{169,170}$ observed mating advantage of rare gene arrangements in certain species.
Interaction between certain chromosome arrangements affects mating speed in D. robusta ${ }^{171}$. There is association between rare male mating advantage and inversion karyotypes in D. ananassae ${ }^{172}$. Singh and Chatterjee C $^{173,174}$ studied mating ability of different inversion karyotypes derived from various populations of $D$. ananassae. Heterosis was observed with respect to male mating ability, but there was no variation for females. Further, it was found that chromosomes occurring in high frequency in natural populations were associated with greater mating success in $D$. ananassae. These results suggested that there is a partial behavioural basis of inversion polymorphism in D. ananassae and in comparison to females, males show more variation and thus subject to greater intrasexual selection than females ${ }^{173,174}$.

\section{Overlapping inversions and phylogeny in certain species}

In certain species, there are a number of paracentric inversions which fall under the category of overlapping inversions. These are D. azteca, D. pseudoobscura and $D$. persimilis which belong to the same species group. In these species, inversion phylogeny has been discussed on the basis of overlapping inversions. In such phylogeny, each sequence differs from the next by a single inversion. Phylogenetic charts of different sequences have been given by Dobzhansky and Sokolov ${ }^{175}$ for D. azteca and Dobzhansky $^{105}$ for D. pseudoobscura and D. persimilis. Details of these charts may also be found in White ${ }^{1}$. In D. azteca, seven sequences are known in A-chromosome. $D$. pseudoobscura and D. persimilis are closely related sibling species. There are 21 sequences in D. pseudoobscura and 11 in D. persimilis in the third chromosome ${ }^{176}$. The Standard sequence is common in both the sibling species.

\section{Inversion polymorphism in Hawaiian species}

About 700 species of the family Drosophilidae which are endemic to the Hawaii Islands have been described earlier $^{177}$. About 100 species belonging to subgenus Drosophila are picture winged species, which have been extensively studied cytologically and from an evolutionary view point. The results of these studies have yielded interesting information pertaining to picture winged species found in the Hawaiian Islands ${ }^{178-192}$. Studies have been conducted on inversion polymorphism in these species. The intra- and interspecific inversion polymorphism have been compared and about one-third of species were found to be polymorphic for inversions. Certain unique features of these species are: there are homosequencial species having identical banding pattern in polytene chromosomes which occur in clusters: 19 clusters of from 2 to 10 species each. However, these species may be 


\section{REVIEW ARTICLES}

different from one another morphologically, and physiologically and may be distant with respect to other genetic measures. The feature of pattern of inversion polymorphism in these species is the presence of fixed inversions which are useful in inferring their phylogenetic relationships. It has also been suggested that chromosomal aberrations occur in clusters or bursts, probably due to action of transposable elements as revealed by molecular data. In these species, paracentric inversions are unique and are of monophyletic origin. Another uniqueness of these inversions is that even a short inversion may cover very large number of base pairs in the DNA. Thus inversions permit the monitoring of natural selection, crossing-over and fate in populations of a large genome segment of the species ${ }^{183}$. The chromosome phylogeny based on banding pattern, chromosome breaks and fixed inversions has been discussed in different species subgroups: D. grimshawi, D. hawaiiensis, D. glabriapex, D. planitibia, D. adiostola, D. punalua and D. primaeva.

Phylogenetic relationships among different species have also been discussed on the basis of founder events and the pattern of mode of mating preference in which the role of random genetic drift has been suggested ${ }^{183,193}$. Kaneshiro $^{177}$ suggested that the studies on cytogenetics, genetics, ecology, behaviour, morphology, evolution, etc. in these species which are endemic to the Hawaiian Islands resulted in better understanding of these aspects, which was the basis of revising the generic concept of the groups. Later studies concerning phylogeny employing modern tools in the area of molecular biology have proved the monophyletic relationships among species of this group. It has also been suggested that the Hawaiian Drosophila is an evolutionary model clade, and it provides a prospectus for future studies in this direction on microbial interactions and genomics ${ }^{191}$. It has also been suggested that most groups and subgroups within this clade are monophyletic ${ }^{192,194}$.

\section{Chromosome inversions, allozyme and DNA polymorphisms}

Although inversion polymorphism has been studied in detail in different species of Drosophila, it is also correlated with molecular data concerning allozyme and DNA polymorphism. Chromosome inversions were detected in Drosophila in the beginning of the last century through the suppression of crossing-over ${ }^{9,10}$. After extensive studies of chromosomal polymorphism due to paracentric inversions in a large number of species, more studies were initiated to reveal genetic polymorphism at the level of proteins and DNA ${ }^{195,196}$. Lewontin and Hubby ${ }^{195}$ made a conceptual breakthrough in the field of molecular population genetics by providing numerical estimates of genic variations in natural populations of D. pseudoobscura through the study of allozyme polymorphism. Since then, numerous cases of protein (enzyme) polymorphisms caused by different alleles of the same locus through the technique of gel electrophoresis have been reported in a large number of Drosophila species ${ }^{28,197}$. Allozyme is the name given to enzymes which differ in electrophoretic mobility caused due to allelic differences of a single gene. Allozyme polymorphism has been extensively studied in Drosophila, and results of this analysis in about 50 species have revealed that a large number of loci are polymorphic $^{28,197}$. Genetic polymorphism at the level of DNA has also been studied in different Drosophila species employing various methods. Interesting data have been obtained in nucleotide sequence variations and comparison has been made using these results in different populations of the same species as well as in populations of different species ${ }^{28}$. Basically, two methods are used to study DNA polymorphism: RFLP (restriction fragment length polymorphism) which detects restriction sites in DNA with the help of restriction enzymes and separating the restriction fragments using electrophoresis (Southern blot using probe DNA molecule), and DNA sequence variation may be studied using Maxam-Gilbert sequencing method or Sanger dideoxy sequencing method. Different studies in Drosophila species have demonstrated nucleotide sequence variation in natural populations ${ }^{196,198-201}$. Interestingly, there are correlations of molecular data with inversion polymorphism in various species of Drosophila, and a few cases are cited here. There are reports demonstrating that linkage disequilibrium may be present between the inversions themselves and allozyme loci included within the inversion in certain cases $^{202-211}$. Allozyme loci are frequently found nonrandomly associated with chromosomal inversions in which they are included, and there is evidence for the occurrence of seasonal cycles of allozymes within inversions reflecting the operation of natural selection in D. subobscura ${ }^{212}$. Inversions are also correlated with molecular markers in certain cases. In D. pseudoobscura, the concept of genetic coadaptation is supported by molecular data and nucleotide diversity, where epistatic selection maintains genes along a particular gene arrangement ${ }^{132}$. Kennington et al. ${ }^{137}$ reported the pattern of genetic variations and linkage disequilibrium in 24 molecular markers located within In (3R) Payne in D. melanogaster, which is indicative of genetic coadaptation. With the help of multiple whole-genome sequence data in D. pseudoobscura, D. persimilis and D. miranda, it has been demonstrated that genetic variation is affected by chromosomal inversions, and reduction of recombination in heterokaryotypes partly facilitates the process of speciation $^{213}$. Studies on gene expression in D. pseudoobscura by Fuller et al. ${ }^{138}$ demonstrated that chromosomal rearrangements have captured sets of genes which differ in their expression levels extending evidence that for selection of arrangements of genes, the gene expression is a potential target. The effect of two common cosmopolitan inversions on pattern of transcriptional 
variations in D. melanogaster has been studied by Lavington and Kern ${ }^{214}$, who found that transcript abundance for hundreds of genes across the genome is affected significantly by each inversion and inversionaffected loci appear both on unlinked chromosomes and also within inversion. There are recent molecular mapping studies which show that there may be linkage disequilibrium between areas within inversions well away from breakpoints with each other, and these areas may contain genes which are under natural selection that cause spread and fixation of inversions in populations ${ }^{215}$. Kennington and Hoffmann ${ }^{216}$ presented molecular data pertaining to microsatellite loci and Adh locus within inversion in D. melanogaster in different populations from Australia, and found significant differentiation between ST and inverted arrangements in them, which suggest that allelic contents within inversions may vary in different populations. Kapun et al. $^{217}$ have shown that selection plays an important role in the increase of inversion frequencies over time with the help of diagnostic molecular data in D. melanogaster. They also found the existence of frequency clines for certain inversions in both North America and Australia. Further, data on genomic evidence for adaptive inversion clines have been provided in D. melanogaster ${ }^{218}$. The geographic origin and age of inversions in D. melanogaster were estimated with the help of population genomic data which demonstrated that inversions had newly arisen and most of them originated in Africa, which is consistent with the demography of the species $^{219}$. It has also been found that the inversions are ubiquitous in Drosophila, and suppress and redistribute crossing-over and have specific effect on nucleotide variation which is important for DNA variation level ${ }^{220}$. Inversion polymorphisms in the third chromosome of $D$. pseudoobscura were used, and nucleotide diversity of different genetic markers near and away from breakpoints were analysed. It was found that markers within the proximal region of the chromosome had low level of nucleotide diversity than those in the distal region of the chromosome. The level of linkage disequilibrium was greater in the central region of the chromosome compared to proximal and distal regions as in this region there is greater suppression of recombination which does not fully support the idea that genetic exchange is the only factor which influences genetic variation on inverted chromosomes $^{221}$. Gomez and Hasson ${ }^{222}$ analysed the distribution of nucleotide variation among three chromosomal arrangements in D. buzzatii, and found that derived arrangements were less polymorphic than the ancestral one and that the widely distributed arrangements are genetically differentiated. Further, with the help of nucleotide variability it was also shown that inversions are unlikely to be long-lived, balanced polymorphisms ${ }^{223}$. In the $D$. virilis group, it has been reported that genomic location of mobile genetic elements shows a statistically significant association with the breakpoints of inver- sions $^{224}$. As suggested by Schlotterer et al. ${ }^{225}$, the evolve and resequence ( $\mathrm{E}$ and $\mathrm{R}$ ) is a new approach to study the genomic responses to selection during experimental evolution. D. simulans is chromosomally monomorphic (without segregating inversions) and has a greater level of recombination. Because of these characteristics, it is more suitable to study evolve and resequence which is used to test adaptive response of genetic variations ${ }^{226}$.

\section{Origin of inversions}

Although the spontaneous origin of inversions in nature is not clear, aberrations may be induced in the laboratory by treating the flies with mutagens, particularly ionizingradiations. There is a chance that the gene pool of a species may include any aberration originating in nature spontaneously, if it is favoured by natural selection. Certainly, inversions are adaptive because they contain adaptive blocks of genes. It is also not clear how much adaptive effects of chromosome inversion can initiate the origin of inversions. However, two hypotheses have been proposed: postadaptation and preadaptation to throw some light on the origin of inversions. The postadaptation hypothesis is related to position effects and predaptation hypothesis depends on coadaptation which may already be established even in the absence of inversion. If the genes are tightly linked to each other and selection favours certain combinations of genes, then a stable linkage disequilibria may be established ${ }^{227}$. Any inversion which by chance includes such a preadapted groups of genes will become selectively favoured because of its suppression of crossing-over in heterokaryotypes ${ }^{228}$. Further, it has also been suggested that certain sites in the chromosome may have specificity for its breakage. Evidences in favour of these suggestions have been provided $^{10}$. Although different views are suggested for the origin of inversions, it is not clear how inversions originate spontaneously in nature. Future work may provides a clear picture about this phenomenon. Puerma et al. ${ }^{229}$ have suggested that additional structural changes occurring at different timescales may in general disrupt inversion breakpoint regions in D. subobscura.

\section{Conclusion}

In Drosophila, about 1500 species have been described. There is a possibility that more species may be described in future. Thus, there is a rich species diversity at the global level ${ }^{70}$. Chromosomal polymorphism due to paracentric inversions has been detected in about a 100 species in their natural populations. Numerous species are chromosomally monomorphic as they do not contain inversions in their natural populations. Different species vary in their pattern of inversion polymorphism. It is well demonstrated that inversion polymorphism is adaptive 


\section{REVIEW ARTICLES}

and has been considered as a device to adjust with environmentsl diversity. Sometimes very closely related species may vary in their pattern of inversion polymorphism. There are intra- and interspecific variations in the degree of inversion polymorphism. Inversion polymorphism may be rigid or flexible. Inversions may show geographic, latitudinal, altitudinal and seasonal variations in their frequencies. In certain species, central and marginal populations may vary in their degree of polymorphism. For their adjustment with the environment, even the closely related species might have evolved various mechanisms. Inversion polymorphism has also been studied in laboratory populations, and the results have demonstrated that heterosis is associated with inversions, which leads to balanced polymorphism. While using inversions, different phenomena in the area of population genetics, evolution and behaviour genetics have also been studied. Inversion polymorphism has also been discussed in the Hawaiian species as well as their relation with molecular data with respect to allozyme and DNA polymorphism. There is extensive literature on this topic, but the present author has limited the number of references in this article which summarizes research on chromosome inversions in Drosophila during the last 100 years. The work done so far provides extensive evidence for the existence of genetic polymorphism in various species of Drosophila, although the degree of polymorphism may vary in different species. The role of different evolutionary forces has also been demonstrated in the maintenance of these polymorphisms. It is hoped that the research in this field will continue in future and data will be provided for understanding the mechanisms of evolution. Genetic polymorphisms may be useful to derive inferences about the functioning of evolutionary processes.

1. White, M. J. D., Animal Cytology and Evolution, Cambridge University Press, Cambridge, UK, 1973.

2. Ayala, F. J. and Coluzzi, M., Chromosome speciation: humans, Drosophila and mosquitoes. Proc. Natl. Acad. Sci. USA, 2005, 102, 6535-6542.

3. White, M. J. D., Modes of Speciation, Freeman Press, San Francisco, 1978.

4. de Vries, H., Die Mutationstheorie, Veit, Leipzig, Germany, 1901.

5. Da Cunha, A. B., Chromosomal variation and adaptation in insects. Annu. Rev. Entomol., 1960, 5, 85-110.

6. Sperlich, D. and Pfriem, P., Chromosomal polymorphism in natural and experimental populations. In The Genetics and Biology of Drosophila (eds Ashburner, M., Carson, H. L. and Thompson Jr, J. M.), Academic Press, New York, USA, 1986, vol. 3e, pp. 257309.

7. Singh, B. N., Chromosomal variability in Drosophila. In Perspectives in Entomological Research (ed. Agarwal, O. P.), Scientific Publishers, Jodhpur, 1994, pp. 177-188.

8. Powell, J. R., Progress and Prospects in Evolutionary Biology: The Drosophila Model, Oxford University Press, New York, USA, 1997.

9. Sturtevant, A. H., Genetic factors affecting the strength of linkage in Drosophila. Proc. Natl. Acad. Sci. USA, 1917, 3, 555558.
10. Sturtevant, A. H., A crossover reducer in Drosophila melanogaster due to inversion of a section of the third chromosome. Biol. Zentralbl., 1926, 46, 697-702.

11. Sturtevant, A. H., Known and probable inverted sections of the autosomes of Drosophila melanogaster. Carnegie Inst. Washington Publ., 1931, 42, 1-27.

12. Beadle, G. W. and Sturtevant, A. H., X Chromosome inversions and meiosis in Drosophila melanogaste. Proc. Natl. Acad. Sci. USA, 1935, 21, 384-390.

13. Painter, T. S., A new method for the study of chromosome rearrangements and the plotting of chromosome maps. Science, 1933, 78, 585-586.

14. Heitz, E. and Bauer, H., Beweise fur chromosomennatur der kernschleifen in den knauelkernen von Bibio hortulanus. Zeit. Zellf. Mikr. Anat., 1933, 17, 67-83.

15. Patau, K., Chromosomenmorphologie bei Drosophila melanogaster and Drosophila simulans und ihre genetische Bedeutung. Naturwiss, 1935, 23, 537-543.

16. Tan, C. C., Salivary gland chromosomes in two races of Drosophila pseudoobscura. Genetics, 1935, 20, 392-402.

17. Koller, P. C., Structural hybridity in Drosophila pseudoobscura. J. Genet., 1936, 32, 79-102.

18. Carson, H. L., Chromosomal morphism in geographically widespread species of Drosophila. In The Genetics of Colonizing Species (eds Baker, H. G. and Stebins, G. L.), Academic Press, New York, USA, 1965, pp. 503-531.

19. Dobzhansky, Th., Adaptive changes induced by natural selection in wild populations of Drosophila. Evolution, 1947, 1, 1-16.

20. Dobzhansky, Th., Genetics of natural populations. XIX. Origin of heterosis through natural selection in populations of Drosophila pseudoobscura. Genetics, 1950, 35, 288-302.

21. Dobzhansky, Th., Burla, H. and Da Cunha, A. B., Adaptive chromosomal polymorphism in Drosophila willistoni. Evolution, $1950,4,212-235$.

22. Da Cunha, A. B. and Dobzhansky, Th., A further study of chromosomal polymorphism in Drosophila willistoni in its relation to environment. Evolution, 1954, 8, 119-134.

23. Carson, H. L., The population genetics of Drosophila robusta. Adv. Genet., 1958, 9, 1-40.

24. Levitan, M., Non-random associations of inversions. Cold Spring Harbor Symp. Quant. Biol., 1958, 23, 251-268.

25. Singh, B. N., Chromosome inversions and linkage disequilibrium in Drosophila. Curr. Sci., 2008, 94, 459-464.

26. Tobari, Y. N. (ed.), Drosophila ananassae: Genetical and Biological Aspects, Japan Scientific Societies Press, Karger, Tokyo, Japan, 1993.

27. Singh, B. N., Population and behaviour genetics of Drosophila ananassae, Genetica, 1996, 97, 321-332.

28. Singh, B. N., Genetic polymorphisms in Drosophila. Curr. Sci., 2013, 105, 461-469.

29. Singh, B. N., The Dobzhansky's concept of genetic coadaptation: Drosophila ananassae is an exception to this concept. J. Genet., 2018, 97, 1039-1046.

30. Sturtevant, A. H. and Dobzhansky, Th., Inversions in the third chromosome of wild races of Drosophila pseudoobscura and their use in the study of the history of the species. Proc. Natl. Acad. Sci. USA, 1936, 22, 448-450.

31. Dubinin, N. P. and Tiniakov, G. G., Structural chromosomal variability in urban and rural populations of Drosophila funebris. Am. Natl., 1946, 80, 393-396.

32. Levitan, M., Chromosome variation in Drosophila robusta. In Drosophila Inversion Polymorphism (eds Krimbas, C. B. and Powell, J. R.), CRC Press, Boca Raton, Florida, USA, 1992, pp. 212-238

33. Levitan, M. and Etges, W. J., Climate change and recent genetic flux in populations of Drosophila robusta. BMC Evol. Biol., 2005, 5, 4; doi:101186/1471-2148-5-4. 
34. Krimbas, C. B. and Loukas, M., The inversion polymorphism in Drosophila subobscura. Evol. Biol., 1980, 12, 163-234.

35. Prevosti, A., Serra, L., Ribo, G., Aguade, M., Sagarra, E., Monclus, M. and Gracia, M. P., The colonization of Drosophila subobscura in Chile. II. Clines in the chromosomal arrangements. Evolution, 1985, 39, 838-844.

36. Krimbas, C. B., The inversion polymorphism of Drosophila subobscura. In Drosophila Inversion Polymorphism (eds Krimbas, C. B. and Powell, J. R.), CRC Press, Boca Raton, Florida, USA, 1992, pp. 127-220.

37. Santos, M., Recombination load in a chromosome inversion polymorphism of Drosophila subobscura. Genetics, 2009, 181, 803-809.

38. Beckenbach, A. T. and Prevosti, A., Colonization of North America by the European species Drosophila subobscura and D. ambigua. Am. Midl. Nat., 1986, 115, 10-18.

39. Ayala, F. J., Serra, L. and Prevosti, A., A grand experiment in evolution: the Drosophila subobscura colonization of the America. Genome, 1989, 31, 246-255.

40. Prevosti, A., Ribo, G., Serra, L., Aguade, M., Balana, J., Monclus, M. and Mestres F, Colonization of America by Drosophila subobscura: experiment in natural populations that supports the adaptive role of chromosomal inversion polymorphism. Proc. Natl. Acad. Sci. USA, 1988, 85, 5597-5600.

41. Mukai, T., Watanabe, T. K. and Yamaguchi, O., The genetic structures of natural populations of Drosophila melanogaster XII Linkage disequilibrium in a large local population. Genetics, 1974, 77, 771-793.

42. Stalker, H. D., Chromosome studies in wild populations of Drosophila melanogaster. Genetics, 1976, 82, 323-347.

43. Mettler, L. E., Voelker, R. A. and Mukai, T., Inversion clines in populations of Drosophila melanogaster. Genetics, 1977, 87, $169-176$

44. Voelker, R. A., Mukai, T. and Johnson, F. M., Genetic variations in populations of Drosophila melanogaster from the western United States. Genetica, 1977, 47, 143-148.

45. Choi, Y., Chromosomal polymorphism in a Korean natural populations of Drosophila melanogaster. Genetica, 1977, 47, 155-160.

46. Inoue, Y. and Watanabe, T. K., Inversion polymorphism in Japanese natural populations of Drosophila melanogaster. Jpn. J. Genet., 1979, 54, 69-82.

47. Knibb, W. R., Oakeshott, J. G. and Gibson, J. B., Chromosome inversion polymorphism in Drosophila melanogaster. I Latitudinal clines and associations between inversions in Australasian populations. Genetics, 1981, 98, 833-847.

48. Knibb, W. R., Chromosome inversion polymorphism in Drosophila melanogaster. II. Geographic clines and climatic associations in Australasia, North America and Asia. Genetica, 1982, 58, 213-221.

49. Das, A. and Singh, B. N., Chromosomal polymorphism in Indian natural populations of Drosophila melanogaster. Korean $J$. Genet., 1991, 13, 97-112.

50. Das, A. and Singh, B. N., Genetic differentiation and inversion clines in Indian natural populations of Drosophila melanogaster. Genome, 1991, 34, 618-625.

51. Singh, B. N. and Das, A., Inversion polymorphism in Indian natural populations of Drosophila melanogaster. Genome, 1990, 33, 311-316.

52. Singh, B. N. and Das, A., Further evidence for latitudinal inversion clines in natural populations of Drosophila melanogaster from India. J. Hered., 1992, 83, 227-230.

53. Lemeunier, F. and Aulard, S., Inversion polymorphism in Drosophila melanogaster. In Drosophila Inversion Polymorphism (eds Krimbas, C. B. and Powell, J. R.), CRC Press, Boca Raton, Florida, USA, 1992, pp. 339-406.

54. Aulard, S., David, J. R. and Lemeunier, F., Chromosomal inversion polymorphism in Afrotropical populations of Drosophila melanogaster. Genet. Res., 2002, 79, 49-63.
55. Ashburner, M. and Lemeunier, F., Relationships within the melanogaster species group of the genus Drosophila (Sophophora). I. Inversion polymorphism in Drosophila melanogaster and Drosophila simulans. Proc. R. Soc. London Ser. B, 1976, 193, 137-157.

56. Stalker, H. D., Chromosome studies in wild populations of Drosophila melanogaster. II Relationships of inversion frequencies to latitude, season, wing loading and flight activity. Genetics, 1980, 95, 211-223.

57. Inoue, Y., Watanabe, T. and Watanabe, T. K., Evolutionary change of the chromosomal polymorphism in Drosophila melanogaster populations. Evolution, 1984, 38, 753-765.

58. Singh, B. N., Patterns of inversion polymorphism in three species of the Drosophila melanogaster species group. Indian J. Exp. Biol., 2001, 39, 611-622.

59. Singh, B. N., Drosophila ananassae - a species characterized by several unusual genetic features. Curr. Sci., 2000, 78, 391398.

60. Singh, B. N., Drosophila ananassae: a good model species for genetical, behavioural and evolutionary studies. Indian J. Exp. Biol., 2010, 48, 333-345.

61. Singh, B. N., Drosophila ananassae - why it is considered as a unique species in the genus Drosophila. Curr. Sci., 2018, 114, $11-12$.

62. Singh, B. N., Drosophila ananassae - a genetically unique species. Nucleus, 1985, 28, 169-176.

63. Ray-Chaudhuri, S. P. and Jha, A. P., Genetics of Indian populations of Drosophila ananassae. Nucleus, 1967, 10, 81-89.

64. Singh, B. N., Distribution of most common inversions of Drosophila ananassae in different parts of India including Andaman and Nicobar Islands. Indian Biol., 1970, 2, 78-81.

65. Singh, B. N., Quantitative variation of chromosomal polymorphism in natural populations of Drosophila ananassae. Cytologia, 1974, 39, 309-314.

66. Singh, B. N., High frequency of cosmopolitan inversions in natural populations of Drosophila ananassae from Kerala, South India. J. Hered., 1984, 75, 504-505.

67. Singh, B. N., Inversion polymorphism in Indian populations of Drosophila ananassae. Hereditas, 1989, 110, 133-138.

68. Singh, B. N., Population genetics of inversion polymorphism in Drosophila ananassae. Indian J. Exp. Biol., 1998, 36, 739-748.

69. Singh, B. N., Chromosomal polymorphism in Drosophila ananassae: similarity between widely distant populations from India. Korean J. Genet., 1991, 13, 27-33.

70. Singh, B. N., Species and genetic diversity in the genus Drosophila inhabiting the Indian subcontinent. J. Genet., 2015, 94, 351-361.

71. Singh, P. and Singh, B. N., Population genetics of Drosophila ananassae: genetic differentiation among Indian natural populations at the level of inversion polymorphism. Genet. Res., 2007, 89, 191-199.

72. Singh, P. and Singh, B. N., Population genetics of Drosophila ananassae. Genet. Res., 2008, 90, 409-419.

73. Singh, B. N. and Yadav, J. P., Status of research on Drosophila ananassae at global level. J. Genet., 2015, 94, 785-792.

74. Singh, B. N., Genetic distance in inversion polymorphism among natural populations of Drosophila ananassae. Genetica, 1984, 64, 211-224.

75. Singh, B. N., Genetic similarity between natural populations of Drosophila ananassae from Kerala and Andaman and Nicobar Islands. Genetica, 1986, 69, 143-147.

76. Singh, B. N. and Anand, S., Genetic divergence at the level of inversion polymorphism in Indian populations of Drosophila ananassae. Evol. Biol., 1995, 8 and 9, 177-190.

77. Singh, P. and Singh, B. N., Population genetics of Drosophila ananassae. Evidence for population sub-structuring at the level of inversion polymorphism in Indian natural populations. Int. J. Biol. (Canada), 2010, 2, 19-28. 


\section{REVIEW ARTICLES}

78. Reddy, G. S. and Krishnamurthy, N. B., Altitudinal gradients in the frequencies of three common inversions in Drosophila ananassae. Drosoph. Inf. Serv., 1974, 51, 136-137.

79. Singh, B. N., An inversion within the subterminal inversion in Drosophila ananassae. Experientia, 1983, 39, 231-235.

80. Yadav, J. P. and Singh, B. N., Evolutionary genetics of Drosophila ananassae I. Effect of selection on body size and inversion frequencies. J. Zool. Syst. Evol. Res., 2006, 44, 323-329.

81. Bock, I. R., Intra and interspecific chromosomal inversions in the Drosophila bipectinata species complex. Chromosoma, 1971, 34, 206-229.

82. Jha, A. P. and Rahman, S. M. Z., Cytogenetics of natural populations of Drosophila. I. Role of chromosomal inversions in the evolution of the Drosophila bipectinata species complex. Chromosoma, 1972, 37, 445-454.

83. Gupta, J. P. and Panigrahy, K. K., Chromosomal polymorphism in Indian populations of Drosophila bipetinata Duda. Genetica, 1990, 82, 45-49.

84. Singh, B. N. and Das, A., Linkage disequilibrium between inversions in Drosophila bipectinata. Biol. Zentbl., 1991, 110, $157-$ 162 .

85. Das, A. and Singh, B. N., Heterosis associated with chromosome inversions in Drosophila bipectinata. Korean J. Genet., 1992, 14, 173-178.

86. Banerjee, R. and Singh, B. N., Inversion polymorphism in natural populations of Drosophila bipectinata. Cytobios, 1996, 87, 3143.

87. Singh, B. N. and Banerjee, R., Increase in the degree of inversion polymorphism in Drosophila bipectinata populations transferred to laboratory conditions. J. Zool. Syst. Evol. Res., 1997, 35, 153157.

88. Banerjee, R. and Singh, B. N., Evidence for coadaptation in geographic populations of Drosophila bipectinata. J. Zool. Syst. Evol. Res., 1998, 36, 1-6.

89. Tomimura, Y., Matsuda, M. and Tobari, Y. N., Chromosomal phylogeny and geographical divergence in the Drosophila bipectinata complex. Genome, 2005, 48, 487-502.

90. Singh, B. N. and Sisodia, S., Phylogenetic relationship among four members of the Drosophila bipectinata species complex. J. Sci. Res., BHU, 2008, 52, 81-97.

91. Singh, B. N. and Banerjee, P., Population genetical, behavioural and evolutionary studies in the Drosophila bipectinata species complex. Proc. Indian Natl. Sci. Acad., 2016, 82, 99-115.

92. Banerjee, P. and Singh, B. N., The Drosophila bipectinata species complex: phylogenetic relationship among different members based on chromosomal variations. J. Genet., 2017, 96, 97-107.

93. Singh, G. and Singh, A. K., Excessive occurrence of paracentric inversions in a natural population of Drosophila bipectinata. J. Exp. Zool., India, 2018, 21, 29-33.

94. Ranganath, H. A. and Krishnamurthy, N. B., Chromosomal polymorphism in Drosophila nasuta II. Coexistence of heteroselection and flexibility of polymorphic system of South Indian populations. Genetica, 1975, 48, 215-221.

95. Rajasekarasetty, M. R., Ramesh, S. R. and Krishnamurthy, N. B., Inversions in natural populations of Drosophila nasuta. Nucleus, 1979, 22, 92-95.

96. Kumar, A. and Gupta, J. P., Linkage disequilibrium, natural selection and epistatic gene interaction in Drosophila nasuta. Genome, 1988, 30, 495-498.

97. Carson, H. L., Chromosomal morphism in geographically widespread species of Drosophila. In The Genetics of Colonizing Species (eds Baker, H. G. and Stebbins, G. L.), Academic Press, London, UK, 1965, pp. 503-531.

98. Brncic, D., Studies on the evolutionary biology of Chilean species of Drosophila. In Essays in Evolution and Genetics in Honour of Theodosius Dobzhansky (eds Hecht and Steere, W. C), Appleton-Century-Crofts, New York, 1970, pp. 401-436.
99. Brncic, D., Further studies on chromosomal polymorphism in Drosophila pavani. J. Hered., 1973, 64, 175-180.

100. Mather, W. B., Temporal variation in Drosophila rubida inversion polymorphism. Heredity, 1964, 19, 231-234.

101. Brncic, D., Seasonal fluctuations of inversion polymorphism in Drosophila flavopilosa and relationships with certain ecological factors. Univ. Texas Publ., 1972, 7213, 103-116.

102. Borisov, A. I., Adaptive value of chromosomal polymorphism. IV. The prolonged observation on a population of Drosophila funebris in Moscow town. Genetika (Moscow), 1970, 6, 115-122.

103. Levene, H. and Dobzhansky, Th., New evidence of heterosis in naturally occurring inversion heterozygotes in Drosophila pseudoobscura. Heredity, 1958, 12, 37-49.

104. Brncic, D., Integration of the genotypes in geographic populations of Drosophila pavani. Evolution, 1961, 15, 92-97.

105. Dobzhansky, Th., Genetics and the Origin of Species, Third Edition, Columbia University Press, New York, USA, 1951.

106. Spiess, E. B., Experimental populations of Drosophila persimilis from an altitudinal transect of the Sierra Nevada. Evolution, 1950, 4, 14-33.

107. Levitan, M., Experiments on chromosomal variability in Drosophila robusta. Genetics, 1951, 36, 285-305.

108. Dobzhansky, Th. and Pavlovasky, O., An experimental study of interaction between genetic drift and natural selection. Evolution, 1957, 11, 311-319.

109. Tobari, Y. N., Heterosis relating to a terminal inversion in artificial population of Drosophila ananassae. Jpn. J. Genet., 1962, 37, 302-309.

110. Singh, B. N. and Ray-Chaudhuri, S. P., Balanced chromosomal polymorphism in experimental populations of Drosophila ananassae. Indian J. Exp. Biol., 1972, 10, 301-303.

111. Singh, B. N., Persistence of chromosomal polymorphism in various strains of Drosophila ananassae. Genetica, 1982, 59, 151156.

112. Singh, B. N., Evidence for random genetic drift in laboratory populations of Drosophila ananassae. Indian J. Exp. Biol., 1988, 26, 85-87.

113. Singh, B. N., On the degree of genetic divergence in Drosophila ananassae populations transferred to laboratory conditions. Zeit. Zool. Syst. Evol., 1987, 25, 180-187.

114. Das, A. and Singh, B. N., Chromosome inversions in Indian Drosophila melanogaster. Genetica, 1990, 81, 85-88.

115. Singh, B. N. and Das, A., Changes of inversion polymorphism in laboratory populations of Drosophila melanogastaer. Zeit. Zool. Syst. Evol., 1992, 30, 268-280.

116. Singh, B. N. and Banerjee, R., Increase in the degree of inversion polymorphism in Drosophila bipectinata populations transferred to laboratory conditions. J. Zool. Syst. Evol. Res., 1997, 35, 153157.

117. Dobzhansky, Th., Observations and experiments on natural selection in Drosophila (Suppl. Vol.). Hereditas, 1949, pp. 210-224.

118. Dobzhansky, Th., Genetics of natural populations XIX. Origin of heterosis through selection in populations of Drosophila pseudoobscura. Genetics, 1950, 35, 288-302.

119. Dobzhansky, Th., Mendelian populations as genetic systems. Cold Spring Harbor Symp. Quant. Biol., 1957, 22, 385-393.

120. Darlington, C. D. and Mather, K., The Elements of Genetics, Allen and Unwin, London, UK, 1949.

121. Wright, S., Biology and philosophy of science. Monist, 1964, 48, 265-290.

122. Singh, B. N., The Dobzhansky's concept of genetic coadaptation: Drosophila ananassae is an exception to this concept. J. Genet., 2018, 97, 1039-1046.

123. Singh, B. N., Darwin of the 20th century-Mayr or Dobzhansky? Curr. Sci., 2012, 103, 125.

124. Dobzhansky, Th. and Pavlovasky, O., Interracial hybridization and breakdown of coadapted gene complexes in Drosophila 
paulistorum and D. willistoni. Proc. Natl. Acad. Sci. USA, 1958 44, 622-629.

125. Singh, B. N. and Banerjee, R., Chromosomal variability and interracial hybridization in Drosophila bipectinata. Cytobios, 1995, 82, 219-227.

126. Kumar, A. and Gupta, J. P., Heterosis and the lack of coadaptation in Drosophila nasuta. Heredity, 1991, 67, 275-279.

127. Singh, B. N., The lack of evidence for coadaptation in geographic populations of Drosophila ananassae. Genetica, 1972, 43, 582588.

128. Singh, B. N., Persistence of heterosis in crosses between geographic races of Drosophila ananassae. Indian J. Exp. Biol., 1974, 12, 376-377.

129. Singh, B. N., Interracial hybridization in Drosophila ananassae. Genetica, 1981, 57, 139-142.

130. Singh, B. N., Heterosis without selectional coadaptation in Drosophila ananassae. Theor. Appl. Genet., 1985, 69, 437-441.

131. Carson, H. L., Heterosis and fitness in experimental populations of Drosophila melanogaster. Evolution, 1961, 15, 496-509.

132. Schaeffer, S. W. et al., Evolutionary genomics of inversions in Drosophila pseudoobscura: evidence for epistasis. Proc. Natl. Acad. Sci. USA, 2003, 100, 8319-8324.

133. Hoffmann, A. A., Sagro, C. M. and Weeks, A. R., Chromosomal inversion polymorphism and adaptation. Tends Ecol. Evol., 2004, 19, 422-488

134. Barker, J. S. F., Inter-locus interaction: a review of experimental evidence. Theor. Popul. Biol., 1979, 16, 323-346.

135. Singh, B. N., Genetic coadaptation in Drosophila. Indian Rev. Life Sci., 1991, 11, 205-231.

136. Zivanovic, G., Andjelkovic, M. and Marinkovic, D., Genetic load and coadaptation of chromosomal inversions. II. O chromosomes in Drosophila subobscura populations. Hereditas, 2000, 133, 105-113.

137. Kennington, W. J., Partridge, L. and Hoffmann, A. A., Patterns of diversity and linkage disequilibrium within the cosmopolitan inversion in (3R) Payne in Drosophila melanogaster are indicative of coadaptation. Genetics, 2006, 172, 1655-1663.

138. Fuller, Z. L., Haynes, G. D., Richards, S. and Schaffer, S. W., Genomics of natural populations: how differentially expressed genes shape the evolution of chromosomal inversions in Drosophila pseudoobscura. Genetics, 2016, 204, 287-301.

139. Chang, C. and Chang, H., Genetic analysis of parthenogenetic capability and fecundity in Drosophila albomicans. Zool. Stud., 2014, 53, 1-8.

140. Bridges, C. B. and Brehme, K. F., The mutants of Drosophila melanogaster. Carnegie Inst. Washington Publ., 1944, 552.

141. Lindsley, D. L. and Grell, E. H., Genetic Variations of Drosophila melanogaster. Carnegie Inst. Washington Publ., 1968, p. 627.

142. Dobzhansky, Th. and Epling, C., The suppression of crossingover in inversion heterozygotes of Drosophila melanogaster. Proc. Natl. Acad. Sci. USA, 1948, 34, 137-141.

143. Sturtevant, A. H. and Beadle, G. W., The relations of inversions in the X-chromosome of Drosophila melanogaster to crossingover and disjunction. Genetics, 1936, 21, 554-604.

144. Dobzhansky, Th. and Sturtevant, A. H., Translocations between the second and third chromosomes of Drosophila and their beraing on Oenothera problems. Carnegie Inst. Washington Publ., 1931, 421, 29-59.

145. Dobzhansky, Th., Studies on chromosome conjugation II. The relation between crossing over and disjunction of chromosomes. Z. Indukt. Abstramm. Vererbungsl., 1933, 64, 269-309.

146. Grell, R. F., A new model for secondary non-disjunction: the role of distributive pairing. Genetics, 1962, 47, 1737-1754.

147. Komai, T. and Takau, T., Two independent inversions in the $\mathrm{X}$-chromosome of Drosophila virilis and their effects on crossing over and disjunction. Cytologia, 1940, 11, 245-260.
148. Komai, T. and Takau, T., On the effect of the X-chromosome inversions on crossing over in Drosophila virilis. Cytologia, 1942, 12, 357-365.

149. Schultz, J. and Redfield, H., Interchromosomal effect on crossing-over in Drosophila. Cold Spring Harbor Symp. Quant. Biol., 1951, 16, 175-197.

150. Ramel, C., Interchromosomal effects of inversions in Drosophila melanogaster. I. Crossing over. Hereditas, 1962, 48, 1-58.

151. Luccchesi, J. C., Interchromosomal effects. In The Genetics and Biology of Drosophila (eds Ashburner, M. and Novitski, E.), Academic Press, New York, USA, 197, vol. 1a, pp. 315-329.

152. Da Cunha, A. B., Chromosomal polymorphism in the Diptera. Adv. Genet., 1955, 7, 93-138.

153. Singh, B. N. and Singh, A. K., The effects of heterozygous inversions on crossing over in Drosophila ananassae. Genome, 1987, 29, 802-805.

154. Singh, B. N. and Mohanty, S., Intra- and interchromosomal effects of heterozygous inversions on crossing-over in the third chromosome of Drosophila ananassae. Indian J. Exp. Biol., 1991, 29, 23-27.

155. Singh, A. K. and Singh, B. N., Heterozygous inversions and spontaneous male crossing-over in Drosophila ananassae. Genome, 1988, 30, 445-450.

156. Franca, Z. M., Da Cunha, A. B. and Garrido, M. C., Recombination in Drosophila willistoni. Heredity, 1968, 23, 199-204.

157. Sperlich, D. and Freuerbach-Mravlag, H., Epistatic gene interaction, crossing over and linked and unlinked inversions in Drosophila subobscura. Evolution, 1974, 28, 67-75.

158. Singh, B. N., Recombination between heterozygous inversions in Drosophila ananassae. Genetica, 1973, 44, 602-607.

159. Singh, B. N. and Singh, A. K., Crossing-over between linked inversions in Drosophila ananassae. Hereditas, 1988, 109, $15-19$.

160. Singh, B. N. and Mohanty, S., Lack of correlation between crossing-over and chromosome distance between inversions in Drosophila ananassae. Genome, 1990, 33, 592-595.

161. Levitan, M., Position effects in natural populations. Am. Nat., 1954, 88, 419-423.

162. Hedrick, P. W., Genes in Populations, Jones and Bartlett, Sudbury, MA, USA, 2005, 3rd edn.

163. Singh, B. N. and Singh, A. K., Linkage disequilibrium in laboratory strains of Drosophila ananassae is due to drift. Hereditas, 1990, 112, 203-208.

164. Spiess, E. B. and Langer, B., Chromosomal adaptive polymorphism in Drosophila persimilis. III. Mating propensity of homokaryotypes. Evolution, 1961, 15, 535-544.

165. Spiess, E. B. and Langer, B., Mating speed control by gene arrangements in Drosophila pseudoobscura homokaryotypes. Proc. Natl. Acad. Sci. USA, 1964, 51, 1015-1019.

166. Brncic, D. and Koref-Santibanez, S., Mating activity of homoand hetetrokaryotypes in Drosophila pavani. Genetics, 1964, 49, 585-591.

167. Kaul, D. and Parsons, P. A., The genotypic control of mating speed and duration of copulation in Drosophila pseudoobscura. Heredity, 1965, 20, 381-392.

168. Sperlich, D., Unterschiediche Paarungsaktivitat innerhalb und zwischen verschiedensen geographischen stamen von Drosophila subobscura. Z. Verebungsl., 1966, 98, 10-15.

169. Ehrman, L., Mating success and genotype frequency in Drosophila. Anim. Behav., 1966, 14, 332-339.

170. Ehrman, L., The mating advantage of rare males in Drosophila. Proc. Natl. Acad. Sci. USA, 1970, 65, 345-348.

171. Prakash, S., Chromosome interactions affecting mating speed in Drosophila robusta. Genetics, 1968, 60, 589-600.

172. Som, A. and Singh, B. N., Rare male mating advantage for inversion karyotype in Drosophila ananassae. Behav. Genet., 2004, 34, 335-342. 


\section{REVIEW ARTICLES}

173. Singh, B. N. and Chatterjee, S., Mating ability of homo- and heterokaryotypes of Drosophila ananassae from natural populations. Heredity, 1986, 57, 75-78

174. Singh, B. N. and Chatterjee, S., Parallelism between male mating propensity and Chromosome arrangement frequency in natural populations of Drosophila ananassae. Heredity, 1988, 60, 269272.

175. Dobzhansky, Th. and Sokolov, D., Structure and variation of the chromosome in Drosophila azteca. J. Hered., 1939, 30, 3-19.

176. Kastritsis, C. D. and Crumpacker, D. W., Gene arrangements in the third chromosome of Drosophila pseudoobscura. J. Hered. 1967, 58, 113-129.

177. Kaneshiro, K. Y., RCL Perkins' legacy to evolutionary research on Hawaiian Drosophilidae (Diptera). Pac. Sci., 1997, 51, 450461 .

178. Cason, H. L., Chromosomal races of Drosophila crucigera from the islands of Oahu and Kauai, State of Hawaii. Univ. Texas Publ., 1966, 6615, 405-412.

179. Carson, H. L., Ancient chromosomal polymoprphism in Hawaiian Drosophila. Nature, 1973, 241, 200-202.

180. Carson, H. L., Patterns of speciation in Hawaiian Drosophila inferred from ancient chromosomal polymorphism. In Genetic Mechanisms of Speciation in Insects (ed. White, M. J. D.) Australia and New Zealand Book, Sydney, Australia, 1987, pp. 81-93.

181. Carson, H. L., Chromosomal tracing of evolution in a phylad of species related to Drosophila hawaiiensis. In Evolution and Speciation (eds Atchley, W. R. and Woodruff, D.), Cambridge University Press, New York, USA, 1981.

182. Carson, H. L., Tracing ancestry with chromosomal sequences. Trends Ecol. Evol., 1987, 2, 203-207.

183. Carson, H. L., Inversions in Hawaiian Drosophila. In Drosophila Inversion Polymorphism (eds Krimbas, C. B. and Powell, J. R.) CRC Press, Boca Raton, Florida, USA, 1992, pp. 407-439.

184. Carson, H. L., Clayton, F. E. and Stalker, H. D., Karyotypic stability and speciation in Hawaiian Drosophila. Proc. Natl. Acad. Sci. USA, 1967, 57, 1280-1285.

185. Carson, H. L. and Stalker, H. D., Polytene chromosome relationships in Hawaiian species of Drosophila. Univ. Texas Publ., 1968, 6818, 335-354.

186. Kaneshiro, K. Y., Carson, H. L., Clayton, F. E. and Heed, W. B., Niche in a pair of homosequential Drosophila species from the island of Hawaii. Am. Nat., 1973, 107, 766-774.

187. Cradock, E. M. and Johnson, W. E., Chromosomal and allozymic diversity in Drosophila silvestris and its homosequential species. Evolution, 1979, 33, 137.

188. DeSalle, R., Giddings, L. V. and Kaneshiro, K. Y., Mitochondrial DNA variability in Natural populations of Hawaiian Drosophila. II. Genetic and phylogenetic relationships of natural populations of D. silvestris and D. heteroneura. Heredity, 1986, 56, 87-96.

189. Ahearn, J. N. and Baimai, V., Cytogenetic study of three closely related species of Hawaiian Drosophila. Genome, 1987, 29, 47.

190. Cradock, E. M. and Carson, H. L., Chromosomal inversion patterning and population differentiation in a young insular species, Drosophila silvestris. Proc. Natl. Acad. Sci. USA, 1989, 86, 4798.

191. O'Grady, P. and DeSalle, R., Hawaiian Drosophila as an evolutionary model clade: days of future past. BioEssays, 2018; doi:10.1002/bies. 201700246, 1-11.

192. O'Grady, P. and DeSalle, R., Phylogeny of the genus Drosophila. Genetics, 2018, 209, 1-25.

193. Kaneshiro, K. Y., Ethological isolation and phylogeny in the planitibia subgroup of Hawaiian Drosophila. Evolution, 1976, 30, $740-745$.

194. O’Grady, P. M. et al., Phylogenetic and ecological relationships of the Hawaiian Drosophila inferred by mitochondrial DNA analysis. Mol. Phylogenet. Evol., 2011, 58, 244-256.
195. Lewontin, R. C. and Hubby, J. L., A molecular approach to the study of genic heterozygosity in natural populations II. Amount of variation and degree of heterozygosity in natural populations of Drosophila pseudoobscura. Genetics, 1966, 54, 595-609.

196. Cross, S. R. H. and Birley, A. J., Restriction endonuclease map variation in the Adh region in populations of Drosophila melanogaster. Biochem. Genet., 1986, 24, 415-433.

197. Kumar, S. and Singh, A. K., Allozyme polymorphism in Drosophila. Proc. Zool. Soc. Kolkata, 2016, 69, 22-31.

198. Kreitman, M., Nucleotide polymorphism at the alcohol dehydogenase locus of Drosophila melanogaster. Nature, 1983, 304, 412-417.

199. Stephan, W. and Langley, C. F., Molecular genetic variation in the centromeric region of the $\mathrm{X}$-chromosome in three Drosophila ananassae populations. I. Contrasts between the vermilion and forked loci. Genetics, 1989, 121, 88-99.

200. Hale, L. R. and Singh, R. S., Contrasting patterns of genetic structure and evolutionary history as revealed by mitochondrial DNA and nuclear gene-enzyme variation between Drosophila melanogaster and D. simulans. J. Genet., 1991, 70, 79-90.

201. Hartl, D. L. and Clark, A. G., Principles of Population Genetics, Sinaaur Associates, Massachusetts, USA, 2007.

202. Lakovara, S. and Saura, A., Genic variation in marginal popuilations of Drosophila subobscura. Hereditas, 1971, 69, 77-82.

203. Prakash, S. and Lewontin, R. C., A moleculkar approact to the study of genic heterozygosity in natural populations. V. Further direct evidence of coadaptation in inversions of Drosophila. Genetics, 1971, 69, 405-408.

204. Loukas, M. and Krimbas, C. B., The genetics of Drosophila subobscura populations. V. A study of linkage disequilibrium in natural populations between genes and inversions of the E chromosome. Genetics, 1975, 80, 331-347.

205. Norman, R. A. and Prakash, S., Developmental variation in amylase allozyme activity associated with chromosome inversions. Genetics, 1980, 95, 1001-1011.

206. Pinsker, W. and Sperlich, D., Geographic pattern of allozyme and inversion polymorphism on chromosome $\mathrm{O}$ of Drosophila subobscur and its evolutionary origin. Genetics, 1981, 57, 51-64.

207. Fontdevila, A., Zapata, C., Alvarez, G., Sanchez, L., Mendez, J. and Enriquez, I., Genetic coadaptation in the chromosomal polymorphism of Drosophila subobscura. I. Seasonal changes of genetic disequilibrium in natural populations. Genetics, 1983, 105, 935-955.

208. Cabrera, V. M., Gonzalez, A. M., Laruga, J. M. and Vega, C., Linkage disequilibrium in chromosome A of Drosophila subobscura. Genetica, 1983, 61, 3-8.

209. Barker, J. S. F., East, P. D. and Weir, B. S., Temporal and microgeographic variation in allozyme frequencies in natural populations of Drosophila buzzatii. Genetics, 1986, 112, 577-611.

210. Zapata, C., Alvarez, G., Dosdil, M. and Fontdevila, A., Genetic coadaptation in the chromosomal polymorphism of Drosophila subobscura. II. Changes of gametic disequilibrium in experimental populations. Genetica, 1986, 71, 149-160.

211. Rodriguez, C., Piccinali, R., Levy, E. and Hasson, E., Gametic association between inversion and allozyme polymorphism in Drosophila buzzatii. J. Hered., 2001, 92, 382-391.

212. Rodriguez-Trelles, F., Seasonal cycles of allozyme-by-chromosomal-inversion gametic disequilibrium in Drosophila subobscura. Evolution, 2003, 57, 839-848.

213. McGaugh, S. E. and Noor, M. A. F., Genomic impacts of chromosomal inversions in parapatric Drosophila species. Philos. Trans. R. Soc. London, Ser. B, 2012, 367, 422-429.

214. Levington, E. and Kern, A. D., The effect of common inversion polymorphisms In (2L)t and $\operatorname{In}(3 \mathrm{R})$ Mo on patterns of transcriptional variation in Drosophila melanogaster. G3 Genes/Genomes/ Genetics, 2017, 7, 3659-3668. 
215. Hoffmann, A. A. and Rieseberg, L. H., Revisiting the impact of inversions in evolution: from population genetic markers to driv ers of adaptive shifts and speciation. Annu. Rev. Ecol. Evol. Syst., 2008, 39, 21-42.

216. Kennington, W. J. and Hoffmann, A. A., Patterns of genetic variation across inversions geographic variation in the $\operatorname{In}(2 \mathrm{~L}) \mathrm{t}$ inversion in populations of Drosophila melanogaster from eastern Australia. BMC Evol. Biol., 2013, 13, 100; doi:10.1186/14712148-13-100.

217. Kapun, M., Schalkwyk, H. V., Mcallister, B., Flatt, T. and Schlotterer, C., Inference of chromosomal inversion dynamics from Pool-seq data in natural and laboratory populations of Drosophila melanogaster. Mol. Ecol., 2014, 23, 1813-1827.

218. Kapun, M., Fabian, D. K., Goudet, J. and Flatt, T., Genomic evidence for adaptive inversion clines in Drosophila melanogaster. Mol. Biol. Evol., 2016, 31, 1317-1336.

219. Corbett-Detig, R. B. and Hartl, D. L., Population genomics of inversion polymorphis in Drosophila melanogaster. PLOS Genetics, 2012, 8, 12-e1003056.

220. Navarro, A., Barbadilla, A. and Ruiz, A., Effect of inversion polymorphism on the neutral nucleotide variability of linked chromosomal regions in Drosophila. Genetics, 2000, 155, 685698.

221. Wallace, A. G., Detweiler, D. and Schaeffer, S. W., Evolutionary history of the third chromosome gene arrangements of Drosophila pseudoobscura inferred from inversion breakpoints. Mol. Biol. Evol., 2011, 28, 2219-2229.

222. Gomez, G. A. and Hasson, E., Transpecific polymorphisms in an inversion linked esterase locus in Drosophila buzzatii. Mol. Biol. Evol., 2003, 20, 410-423.
223. Laayouni, H., Hasson, E., Santos, M. and Fontdevila, A., The evolutionary history of Drosophila buzzatii. XXXV. Inversion polymorphism and nucleotide variability in different regions of the second chromosome. Mol. Biol. Evol., 2003, 20, 931-944.

224. Evgen'ev, M. B. et al., Mobile elements and chromosomal evolution in the virilis group of Drosophila. Proc. Natl. Acad. Sci. USA, 2000, 97, 11337-11342.

225. Schlotterer, C., Kofler, R., Versace, E., Tobler, R. and Franssen, S. U., Combining experimental evolution with next generation sequencing: a powerful tool to study adaptation from standing genetic variation. Heredity, 2015, 114, 431-440.

226. Barghi, N., Tobler, R., Nolte, V. and Schlotterer, C., Drosophila simulans: a species with improved resolution in evolve and resequence studies. G3 Genes/Genomes/Genetics, 2017, 7, 2337-2343.

227. Charlesworth, B., Inversion polymorphism in a two-locus genetic system. Genet. Res., 1974, 23, 259-280.

228. Charlesworth, B. and Charlesworth, D., Selection of new inversion in multilocus genetic systems. Genet. Res., 1973, 21, 167-183.

229. Puerma, E., Orengo, D. J. and Aguade, M., The origin of chromosomal inversions as a source of segmental duplications in the Sophophora subgenus of Drosophila. Sci. Rep., 2016, 6, 30715-1-8.

ACKNOWLEDGEMENTS. The work of the present author cited in this review received financial support from various funding agencies and CAS in Zoology, BHU, Varanasi. I thank the referee for providing helpful comments on the manuscript.

Received 30 November 2018; revised accepted 21 May 2019

doi: $10.18520 / \mathrm{cs} / \mathrm{v} 117 / \mathrm{i} 5 / 761-775$ 